\title{
FACTORS THAT ENHANCED PREVENTION OF MOTHER-TO-CHILD TRANSMISSION OF HIV IN NASARAWA STATE OF NIGERIA USING LOGISTIC, POISSON AND NEGATIVE BINOMIAL REGRESSION MODELS
}

\author{
Monday Osagie ${ }^{1,2}$ Adenomon \& David ${ }^{1}$ Usman
}

\author{
1. Department of Statistics \& NSUK-LISA Stat Lab \\ Nasarawa State University, Keffi, Nigeria \\ 2. Foundation of Laboratory for Econometrics and Applied Statistics of Nigeria (aka \\ FOUND-LEAS-IN-NIGERIA) \\ adenomonmo@nsuk.edu.ng; usmandavidson20@gmail.com \\ Tel: $+2347036990145 ;+2347038461048$ \\ 2. https://orcid.org/0000-0002-9523-8032
}

\begin{abstract}
In Sub-Saharan African Countries such as Nigeria with high prevalence rate, Child HIV/AIDs acquired through Mother-to-Child transmission (MTCT) can be largely prevented by using a well-established prevention programme and scheme. This study examined factors that can enhanced Prevention of Mother-to-Child transmission (PMTCT) in Nasarawa State. To achieve this, structured questionnaire were used to collect data from one hundred and sixteen (116) women attending two (2) primary facilities and two (2) secondary facilities in the State. This study utilized methods of Poisson Regression, Negative Binomial Regression and Logistic Regression Analyses. Results revealed that women with at least a secondary school education, women with husband in military and women with perceived confidentiality of their HIV status significantly enhanced PMTCT of HIV in Nasarawa State while significant proportion of the women attest to the fact that drugs are available in the facilities ( $p$-value $=0.0000<0.05)$. Other factors include mother income level, willingness to continue with PMTCT programme and women in support group can also enhanced PMTCT though they are not significant. This study recommends that the factors identified should be explored by NGOs, Ministry of Health and, Support groups and other relevant agencies since they have the capacity to enhanced PMTCT of HIV in Nasarawa State, Nigeria.
\end{abstract}

Keywords: Prevention of Mother-to-Child transmission (PMTCT), Human Immunodeficiency Virus (HIV), Acquired Immune Deficiency Syndrome (AIDs), Poisson, Negative Binomial, Logistic, Regression

1.

\section{Introduction}

Mother-to-child transmission of HIV is the spread of HIV from HIV-infected woman to her child during pregnancy, childbirth, delivery and breastfeeding. Mother-to-child transmission is most common way that children become infected with HIV (De cock, 2000). Without treatment, if a 
pregnant woman is living with HIV the likelihood of the virus passing from mother-to-child is $15 \%$ to $45 \%$ (NACA, 2019).

MTCT of HIV accounts for a large percentage of infections and Prevention of Mother- to- Child Transmission (PMTCT) coverage in Nigeria falls far below the targeted universal coverage of $80 \%$, and achieving virtual elimination of MTCT by 2021 by National strategic plan (NSP) remains far-fetched if access to the services is not improved upon (NACA, 2019).

The most challenging public health problem is HIV, with statistics of about 36.7 (range, 34.039.8) million persons living with HIV, 1.8 (range, 1.6-2.1) million new infections, and 1 million mortalities by the end of 2016. Infact, over 35 million lives have been lost to HIV and associated infections globally, with sub-Saharan Africa remaining the most affected region, as it accounts for two-thirds of the global total of new HIV infections and with 36.7 million people living with HIV in 2016 (UNAIDS,2017).

This study therefore examined the possible factors that can enhance the prevention of mother-tochild transmission of HIV in Nasarawa State of Nigeria using logistic, Poisson and Negative Binomial Regression Models

\section{Literature Review}

Amoran et al (2012) studied a comparative analysis of teenagers and older pregnant women in the utilization of prevention of mother to child transmission service in western Nigeria. Analytical cross-sectional studies were used with selected pregnant women (52 teenagers and 148 adults) in Shagamu, Ogun state. The findings highlighted that the teenagers' pregnant women who were more vulnerable to HIV/AIDS infection did not utilize PMTCT service as much as the older pregnant women. They recommended that special consideration should be giving to teenagers and those from high socio-economic group in the design scale up programmes to improve uptake of PMTCT.

Malaju et al (2012) took a study on Determinant factors of pregnant mother's knowledge on mother-to-child transmission of HIV and its prevention in Gonder town, North West Ethiopia. Cross-Sectional health institution based study was conducted from July 22nd to August 18th 2011. Their findings indicated that majority of the women knew it is possible to prevent motherto-child transmission of HIV. Recommendation was made on, the need or exerting more effort to teach mothers about MTCT and PMTCT of HIV and there should also be well functioning and assessable health facilities in the country, especially the rural areas.

Nwakaego (2014) studied factors influencing utilization of PMTCT service in the federal Capital territory of Nigeria. Cross-sectional design. The findings, most women that participated in the study are under 35 years, self-employ women also higher than any group. The findings also underscored the importance of on-going awareness of HIV/AIDS, intervention during antenatal visit and beyond. Recommendation, support pregnant women such as HIV counsels and testing (HCT), ART infant feeding option should be packaged under PMTCT services. .

Sampsom (2018) researched on factors influencing male involvement in antenatal care in Shai Osudoku district of the greater Accra region, Ghana. Method used was logistic regression of empirical studies. The study found that majority of the males in Shai was highly involved in 
ANC service of their partners. After controlling for other variables, four factors significantly predicted male involvement, in their spouse/partner's ANC activities which includes male's level of education and income class. The recommendation is that the district health management team in collaboration with community leaders should education campaign with communities to educate community members.

Essel (2018) conducted a research on factors affecting adherence to anti-retroviral therapy among women in selected Health facilities in greater Accra region. Cross-sectional study design was employed. The finding specified adherence to ART treatment among the women seeking treatment in the selected health facilities was poor at about $27 \%$. Socio-cultural factors were found to have negative effect on adherence to ART among the women. He therefore recommended, in other to enhance good adherence to ART among women, the Ghana health service should ensure the effective adherence assessment tools.

\section{Model specification}

In this research work, three models were used for the data analysis namely: Negative Binomial Regression Model (NBRM), Poisson Regression Model (PRM) and Logistic Regression Model (LRM).

\section{The Negative Binomial Regression Models}

The binomial distribution is defined as a discrete distribution of the number of successes in a sequence of independent and identically distributed Bernoulli trials before a specified number of failures are observed. The negative binomial considers the results of a series of trials that can be considered either a success or failure (Shegping \& Gilbert, 2015).

$\operatorname{pr}(\mathrm{x}=\mathrm{x})=\left(\begin{array}{c}\mathrm{k}+\mathrm{x}-1 \\ \mathrm{x}-1\end{array}\right) \mathrm{p}^{\mathrm{k}} \mathrm{q}^{\mathrm{x}} \quad 0 \leq \mathrm{x}<\infty$

The mean, variance, skewness and kurtosis of the distribution are as follows:

$$
\text { mean }=\mathrm{kq} / \mathrm{p} ; \text { ce }=\mathrm{kq} / \mathrm{p}^{2} ; \text { skewness }=(1+q)\left((k q)^{2} ;\right. \text { and }
$$

kurtosis $=3+\frac{6}{k}+\frac{\mathrm{p}^{2}}{k q}$

Negative Binomial regression is often using to model overdispersion in count data (Everitt, 2002).

Binomial regression model has been used by so many researchers because it is the standard choice for basic count data model. We have two basic types of negative binomial models, denoted as NB1 and NB2 (Greene, 2008).

\section{Negative binomial 2 (NB) model}

In literature, the PDF of the NB 2 model is given as (Yang, 2015):

$\mathrm{f}\left(\mathrm{y}_{\mathrm{i}} ; \Psi ; \mu_{\mathrm{i}}\right)=\left(\frac{\mathrm{y}_{\mathrm{i}}+\Psi-1}{\Psi-1}\right)\left(\frac{(\Psi)^{\Psi}}{\mu_{1}+\Psi}\right)\left(\frac{\left(\mu_{i}\right)^{y_{i}}}{\mu_{1}+\Psi}\right)$

Where:

$\Psi=$ Gamma Distribution

$\Gamma=$ Gamma Function

This is the probability mass function of a negative binomial distribution.

The first two moments of the NB 2are as follows: 
$\mathrm{E}\left(\mathrm{y}_{\mathrm{i}} ; \Psi, \mu_{\mathrm{i}}\right)-\mu_{i}$ And

$\ln [\mathrm{L}(\mathrm{y}, \beta)]=\sum_{i=1}^{n}\left(y_{i} \ln \left(\frac{\Psi}{1+\Psi}\right)-\Psi^{-1} \ln (1+\Psi)+\ln \Gamma\left(\mathrm{y}_{\mathrm{i}}+1\right)-\ln \Gamma\left(\Psi^{-1}\right)\right.$

Where $\mu_{i}=\exp \left(x_{i}^{\prime} \beta\right)$

Where the conditional variance is greater than the conditional mean of the outcome variable (overdispersion). In addition, it is clear that when $\psi$ is very large,

$\frac{\mu_{\mathrm{i}}^{2}}{w}, \operatorname{var}\left(\left(\mathrm{y}_{\mathrm{i}}, \Psi ; \mu_{\mathrm{i}}\right), \mu_{i}=E\left(\mathrm{y}_{\mathrm{i}} ; \Psi ; \mu_{\mathrm{i}}\right)\right.$ and the expected value or mean converges to variance.

Poisson Regression Model (PRM):

Poisson distribution is the probability distribution of the number of occurrence, $\mathrm{X}$, of some random event, in an interval of time or space. Given by:

$\operatorname{pr}(\mathrm{X}=\mathrm{x})=\frac{\mathrm{e}^{-\lambda_{\lambda} \mathrm{x}}}{\mathrm{x} !} ; \mathrm{x}=0-, 1 \ldots$ The mean and the variance of the distribution are both $\lambda$. The skewness of the distribution is:

and its kurtosis is $3+1 / \lambda$.

1

In Poisson regression model, we suppose that the $\mu$ is determined by a set of $k$ repressor variables (the $X$ 's).

Note that often, $X_{i}=1$ and $\beta_{1}$ is called the intercept. The regression coefficients $\beta_{1}, \beta_{2}, \ldots, \beta_{k}$ are unknown parameters that are estimated from a set of data. Their estimates are labelled $\beta_{1}, \beta_{2}, . ., \beta_{k}$. Using this notation, the fundamental Poisson regression model for an observation $i$ is written as

$\operatorname{Pr}\left(Y_{i}=Y_{i} \mid u_{i}, t_{i}\right)=\frac{e^{-\mu_{i} t_{i}}\left(\mu_{i} \mathrm{t}_{1}\right)^{\mathrm{yi}_{\mathrm{i}}}}{\mathrm{y}_{\mathrm{i}} !}$

Where

$\mu_{\mathrm{i}}=t_{i}, \mu\left(x_{i}^{\prime} \beta\right)$

That is, for a given set of values of the repressor variables, the outcome follows the Poisson distribution

\section{Logistic regression model (LRM)}

The purpose of using logistic regression in this research work is because it's a multivariate method for modelling relationship between multiple independent variables and categorical dependent variable. The multivariate methods explore a relation between two or more predictors (independent) variables and one outcome (dependent) variable (Kleinbaum \& klien, 2010).

$F(y)=\frac{e^{x}}{1+e^{x}}, x \in \mathbb{R}$

Probability density function of logistic distribution (PDF) is given by:

$f(y)=\frac{e^{x}}{\left(1+e^{x}\right)^{2}}, x \in \mathbb{R}$ 


\section{i. Odds ratio for one event}

Odds of an event are the ratio of the probability that an event will occur to the probability that it will not occur. If the probability of an event occurring is $p$, the probability of the event not occurring is (1-p). Then the corresponding odds are a value given by:

odds of $\{$ event $\}=\frac{p}{1-p}$

\section{ii. Odds ratio for two events}

The odds ratio (OR) is a comparative measure of two odds relative to different events. For two events $\mathrm{A}$ and $\mathrm{B}$, the corresponding odds of $\mathrm{A}$ occurring relative to $\mathrm{B}$ occurring is:

$$
\text { odds ratio }\{\text { A vs. } \mathrm{B}\}=\frac{\text { odds }\{A\}}{\text { odds }\{B\}}=\frac{P_{A \mid 1-P_{A}}}{P_{B \mid 1-P_{B}}}
$$

An odds ratio $(\mathrm{OR})$ is a measure of association between an exposure and an out-come

\section{Data Collection}

Method of data collection was a primary data. The data were collected through a survey using an interviewer administered structured questionnaire method. The questionnaires were administered one-on-one to each respondent by the investigator and his assistants

\section{Analysis and Results}

\section{Table 1: Test for over-dispersion.}

\begin{tabular}{|l|l|l|l|l|l|}
\hline & $\mathrm{N}$ & Minimum & Maximum & Mean & Variance \\
\hline $\begin{array}{l}\text { Number of children } \\
\text { with HIV } \\
\text { Valid N (listwise) }\end{array}$ & 116 & .00 & 4.00 & .3793 & .516 \\
\hline
\end{tabular}

Table 1 above shows test for over-dispersion of the response (Number of children with HIV)

Variables and result revealed overdispersion (variance $>$ mean).

\section{Table 2: Poisson regression for children with HIV}

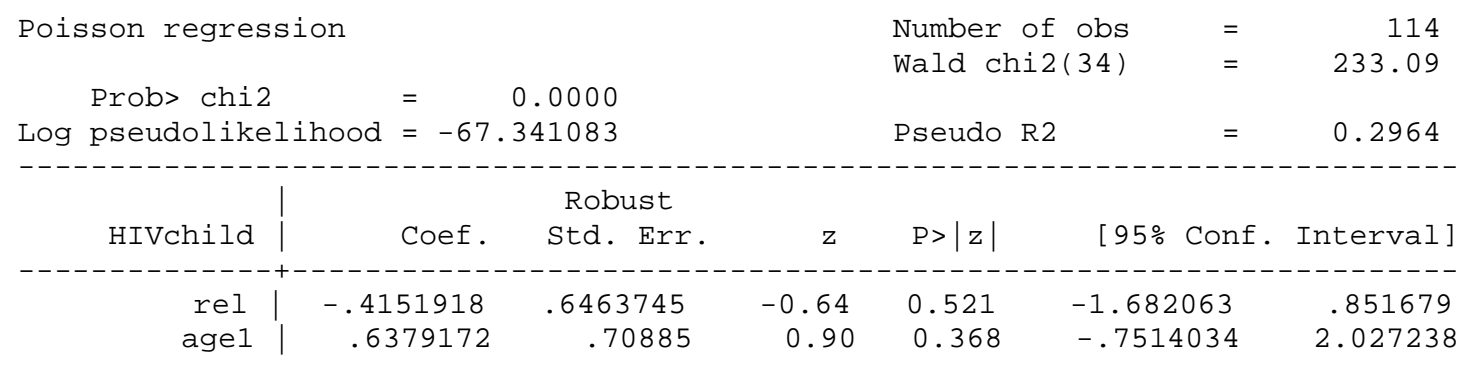




\begin{tabular}{|c|c|c|c|c|c|c|}
\hline age2 & .7985174 & .5853314 & 1.36 & 0.173 & -.348711 & 1.945746 \\
\hline age 3 & .9310406 & .7968468 & 1.17 & 0.243 & -.6307504 & 2.492832 \\
\hline age 4 & .8526455 & .6746592 & 1.26 & 0.206 & -.4696621 & 2.174953 \\
\hline age 5 & 1.52173 & 1.042378 & 1.46 & 0.144 & -.5212942 & 3.564754 \\
\hline marit1 & -.4983637 & .8620398 & -0.58 & 0.563 & -2.187931 & 1.191203 \\
\hline marit 2 & -.2085354 & .9455675 & -0.22 & 0.825 & -2.061814 & 1.644743 \\
\hline marit3 & .4624031 & .9044274 & 0.51 & 0.609 & -1.310242 & 2.235048 \\
\hline edul & .3272905 & .4546861 & 0.72 & 0.472 & -.5638778 & 1.218459 \\
\hline edu2 & -.7486751 & 1.389433 & -0.54 & 0.590 & -3.471914 & 1.974564 \\
\hline edu 3 & .823827 & .4976017 & 1.66 & 0.098 & -.1514544 & 1.799109 \\
\hline edu 4 & -2.483938 & .7480617 & -3.32 & 0.001 & -3.950112 & -1.017764 \\
\hline edu 5 & -.9443637 & .8724405 & -1.08 & 0.279 & -2.654316 & .7655882 \\
\hline Moccup1 & -.4607804 & 1.459048 & -0.32 & 0.752 & -3.320463 & 2.398902 \\
\hline Moccup2 & .8094442 & .7581394 & 1.07 & 0.286 & -.6764817 & 2.29537 \\
\hline Moccup3 & .4706878 & .6325086 & 0.74 & 0.457 & -.7690062 & 1.710382 \\
\hline Moccup 4 & -.7693218 & .6210811 & -1.24 & 0.215 & -1.986618 & .4479747 \\
\hline Mincome1 & -1.090393 & .6295102 & -1.73 & 0.083 & -2.32421 & .1434245 \\
\hline Mincome2 & 1.248262 & 1.112294 & 1.12 & 0.262 & -.9317938 & 3.428318 \\
\hline Hoccup1 & .2453988 & .5189256 & 0.47 & 0.636 & -.7716766 & 1.262474 \\
\hline Hoccup2 & -.9955308 & .9593293 & -1.04 & 0.299 & -2.875782 & .8847202 \\
\hline Hoccup 3 & -3.045572 & 1.289295 & -2.36 & 0.018 & -5.572543 & -.5186008 \\
\hline Hoccup 4 & -.6501139 & .7313386 & -0.89 & 0.374 & -2.083511 & .7832835 \\
\hline Hincome1 & .7471863 & .5890355 & 1.27 & 0.205 & -.4073021 & 1.901675 \\
\hline Hincome 2 & 1.916094 & .7544118 & 2.54 & 0.011 & .4374737 & 3.394714 \\
\hline Hincome 3 & .6198454 & 1.20044 & 0.52 & 0.606 & -1.732973 & 2.972664 \\
\hline Time1 & -.382289 & .3819598 & -1.00 & 0.317 & -1.130917 & .3663386 \\
\hline AwarePMTCT & .7934288 & 1.056556 & 0.75 & 0.453 & -1.277383 & 2.864241 \\
\hline ntinuePMTCT & -.1991605 & .4760549 & -0.42 & 0.676 & -1.132211 & .73389 \\
\hline followupa & .7934496 & .4331456 & 1.83 & 0.067 & -.0555002 & 1.642399 \\
\hline support & -.6451419 & .6419503 & -1.00 & 0.315 & -1.903341 & .6130576 \\
\hline confidence & -2.571557 & .8832397 & -2.91 & 0.004 & -4.302675 & -.8404393 \\
\hline spouseperm & .0903899 & .6474832 & 0.14 & 0.889 & -1.178654 & 1.359434 \\
\hline _C & -.3641718 & 1.424321 & -0.26 & 0.798 & -3.15579 & 2.427447 \\
\hline
\end{tabular}

. estatgof

$\begin{array}{llr}\text { Deviance goodness-of-fit } & = & 64.12863 \\ \text { Prob }>\text { chi2 }(79) & & 0.8874 \\ \text { Pearson goodness-of-fit } & = & 219.4502 \\ \text { Prob }>\text { chi2 }(79) & = & 0.0000\end{array}$

Akaike's information criterion and Bayesian information criterion

\begin{tabular}{|c|c|c|c|c|c|}
\hline Model | & Obsll (null) & 11 (model) & $d f$ & AIC & $\mathrm{BIC}$ \\
\hline & $114-95.7102$ & -67.3410 & & 204.68 & \\
\hline
\end{tabular}

The results of Poisson regression model in table 2 above revealed that a woman with at least a secondary school education (edu 4) is less likely to have a child with HIV positive when compared with a woman without any form of education (edu $4=-2.483938$, $\mathrm{p}$-value $=0.001<0.05$ ). In addition, women whose husband is a military personnel is less likely to have a child with HIV positive status when compared with a woman whose husband is a civil servant (Hoccup=3.045572 , p-value $=0.0018<0.05$ ). Also a woman who perceived that her HIV status is kept confidential is less likely to have a child with HIV positive status when compare to a woman who perceive that her status is not kept confidence (confidence $=-2.571557$, $\mathrm{p}$-value $=0,004<0.05$ )

\section{Table 3: Negative binomial regression with reported IRR}




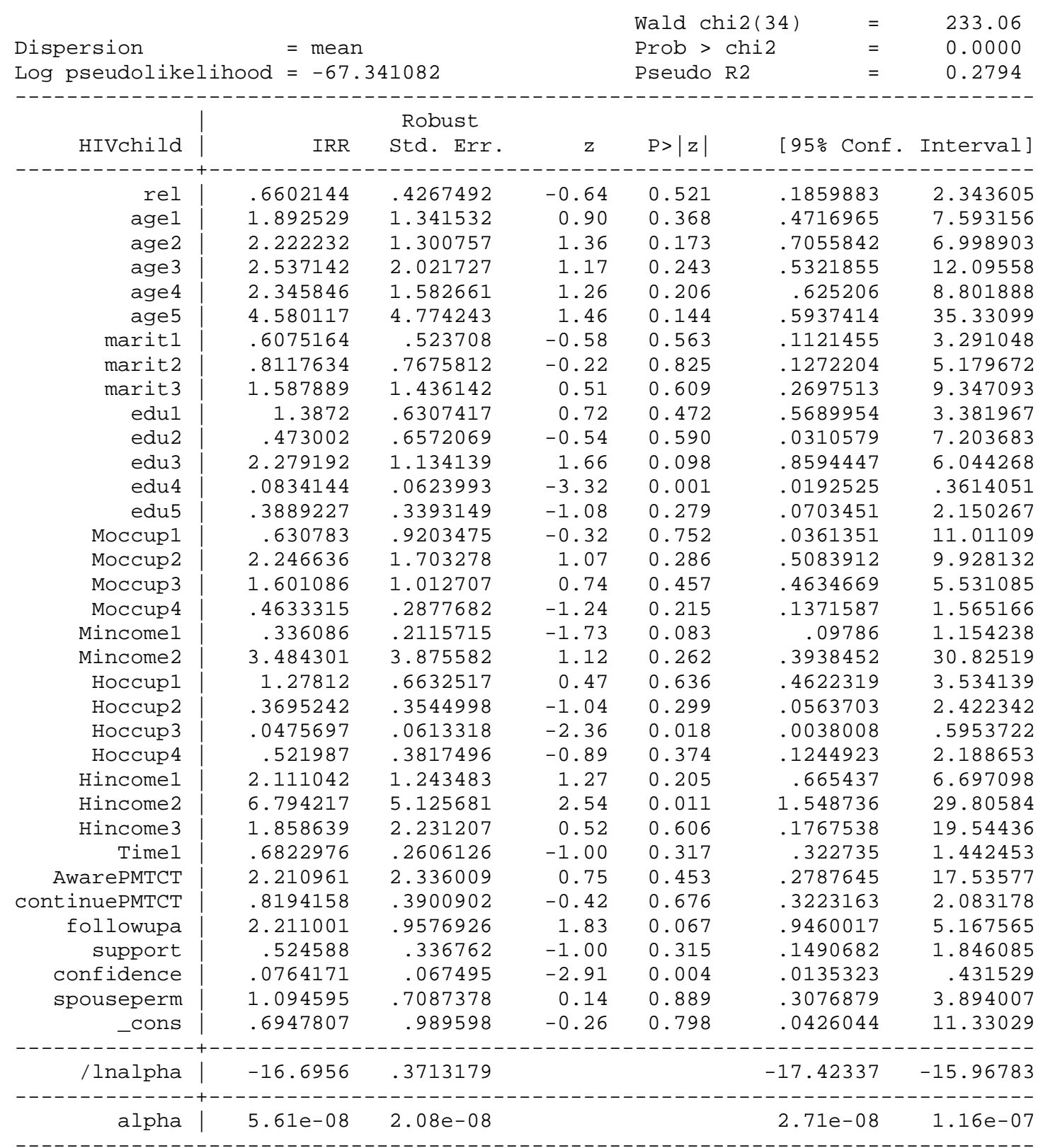

Above result for Negative Binomial regression model in table 3 revealed that a woman with at least a secondary school education (edu 4) is less likely to have a child with HIV positive when compared with a woman without any form of education (edu $4=-2.483935$, $p$-value $=0.001<0.05$ ). In addition, women whose husband is a military personnel is less likely to have a child with HIV positive status when compared with a woman whose husband is a civil servant (Hoccup=3.04556, p-value $=0.0018<0.05$ ). Also a woman who perceived that her HIV status is kept confidential is less likely to have a child with HIV positive status when compare to a woman who perceive that her status is not kept confidence (confidence $=-2.571548$, $p$-value $=0.004<0.05$ ) 
Table 4: logistic regression with reported odd ratio

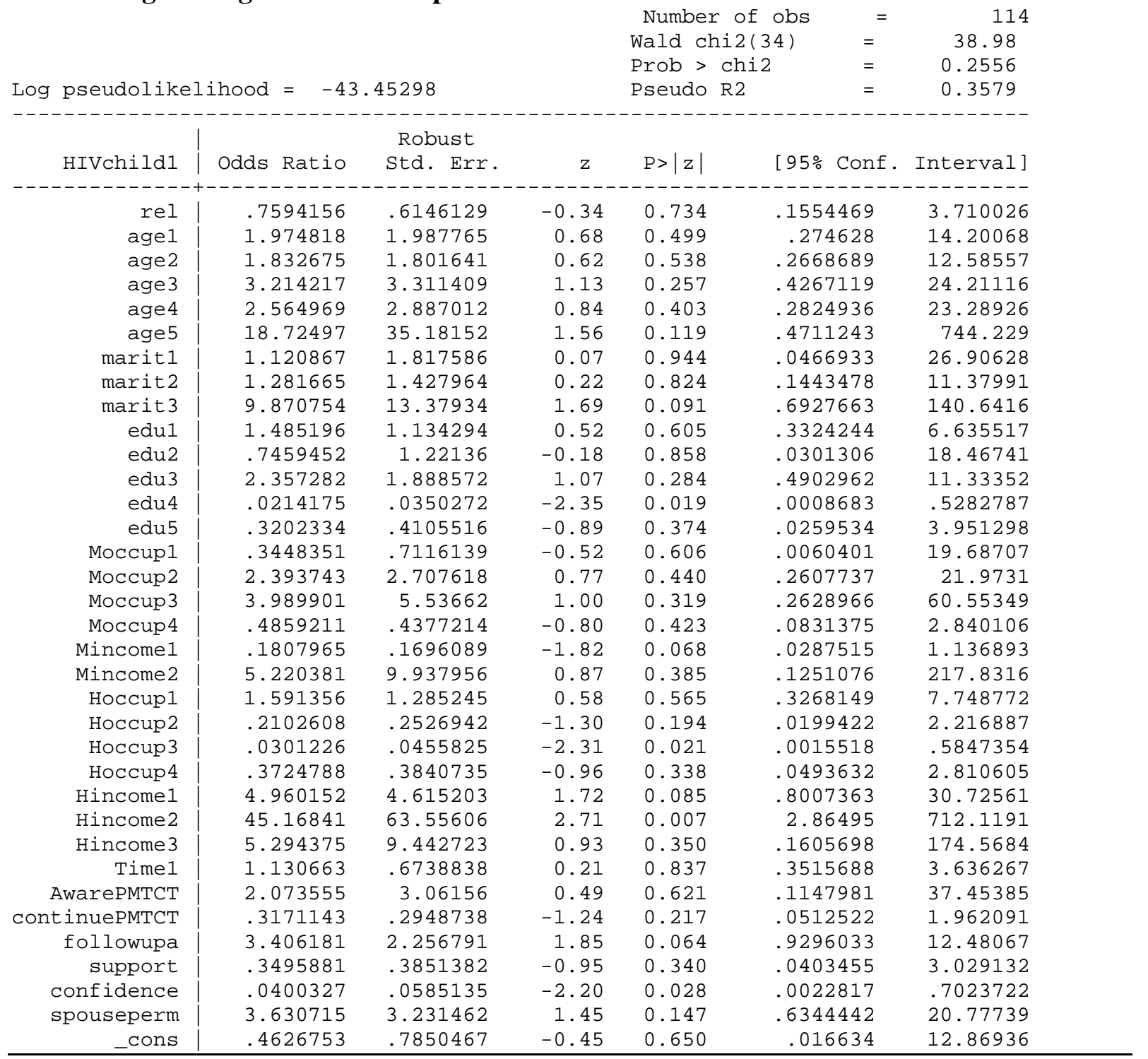

Table 4 revealed the odd ratio for the three controlled variables. The women with secondary school education (edu4 $=0.0259993<1$ ) which means the exposure is negative association and it's less likely to have a child with HIV positive status when compared with a woman whose husband is a civil servant and it decrease HIV prevalence.

In addition, women whose husband is a military personnel is less likely to have a child with HIV positive status when compared with a woman whose husband is a civil servant (Hoccup3=0.0245251<1).

Also, woman who perceived that her HIV status is kept confidential is less likely to have a child with HIV positive status when compare to a woman who perceive that her status is not kept confidence (confidence $=0.0354427<1$ ).

Finally, those variables with odd ratio $>1$ are more likely to increase HIV prevalence among the women and their children and the exposure is positively association. 


\section{Discussion of Results}

The results from the Poisson regression model revealed that a woman with at least a secondary school education (edu 4) is less likely to have a child with HIV positive when compared with a woman without any form of education (edu $4=-2.483938$, p-value $=0.001<0.05$ ).

In addition, women whose husband is a military personnel is less likely to have a child with HIV positive status when compared with a woman whose husband is a civil servant (Hoccup=3.045572 , p-value $=0.0018<0.05)$. Also a woman who perceived that her HIV status is kept confidential is less likely to have a child with HIV positive status when compare to a woman who perceive that her status is not kept confidence (confidence=-2.571557, pvalue $=0,004<0.05)$. This result is in line with the finding of Sampson (2018).

Above result for Negative Binomial regression model in table 3 revealed that a woman with at least a secondary school education (edu 4) is less likely to have a child with HIV positive when compared with a woman without any form of education (edu $4=-2.483935$, p-value $=0.001<0.05$ ). In addition, women whose husband is a military personnel is less likely to have a child with HIV positive status when compared with a woman whose husband is a civil servant (Hoccup=3.04556, p-value $=0.0018<0.05$ ). Also a woman who perceived that her HIV status is kept confidential is less likely to have a child with HIV positive status when compare to a woman who perceive that her status is not kept confidence (confidence=-2.571548, pvalue $=0.004<0.05)$. This result is similar to the study of Eric et al (2019).

Odd ratio from the logistic regression model revealed that the women with secondary school education (edu4=0.0259993<1) which means the exposure is negative association and it's less likely to have a child with HIV positive status when compared with a woman whose husband is a civil servant and it decrease HIV prevalence.

In addition, women whose husband is a military personnel is less likely to have a child with HIV positive status when compared with a woman whose husband is a civil servant (Hoccup3=0.0245251<1).

Also, woman who perceived that her HIV status is kept confidential is less likely to have a child with HIV positive status when compare to a woman who perceive that her status is not kept confidence (confidence $=0.0354427<1$ ).

\section{Conclusion and Recommendations}

The study concludes that the women with secondary school background, wives of military/personnel and those whose HIV status are kept have confidence in the Health facilities were less likely vulnerable to MTCT of HIV services when compared to other factors. Therefore, special consideration should be given to the above variables in order to improve the PMTCT services especially among these vulnerable groups of low income communities. The following are recommended:

i. Prevention of HIV transmission is not enough. It's necessary also to consider ways to improve maternal health and protect child survival and total zero HIV free birth as been stated in national strategic plans of 2017-2021. 
ii. Community sensitization, counselling, effective follow up, tracking of defaults patients and availability of on-site rapid HIV testing kits in every community may encourage those from high socio-economic background to utilize the PMTCT service centres, this will enhance the prevention of MTCT of HIV.

iii. NGOs and the government should intensify campaign and awareness of PMTCT in rural and urban communities in Nigeria.

iv. Education of the girl children and women in Nigeria should be encouraged by Government in Nigeria.

v. More health facilities with PMTCT services be created in rural and urban communities.

\section{REFERENCES:}

Abdi , I.A; Ereg, D; Ali, M. \& Rashenbeck, S.I (2013): Knowledge and attitudes about AIDS/HIV in a semi-normadic population in Somaliland Journal of community health. 38 (2);246-9.

Adeniyi, V.O.; Ajayi, A.I.; Goon, D.T.; Owolabi, E.O.; Eboh, A.; \& Lambert J. (2018): Factors affecting adherence to antiretroviral therapy among pregnant women in the Eastern cape, South Africa. BMC infectious, volume 18:175.

African network on ethics, law and HIS (1995): Proceedings of the inter country

AIDS law project, south Africa (1997): AIDS and the law

Alamu, Y.M; Habteworld, T.D; \& Alamu, S.M. (2018): Mothers knowledge on prevention of Mother-to-child transmission of HIV, Ethiopia. A cross sectional study, pros. One 13(9).

Amoran, O.E.; Salami, O.F.; Oluwole, \& F.A. (2012): A comparative analysis of teenagers and older pregnant women in utilization of prevention of mother to child transmission service in western Nigeria. BMC international Health and Human Rigth 12(1). 13-20/

Asefa,A; \& Mitike, G. (2014): prevention of mother-to-child transmission (PMTCT) of HIV services in Adama town, Ethiopia: Clients satisfaction and chllangeseperienceed by service providers. BMC pregnancy and childbirth 14(1):57

Asefa, A.; \& Beyene, H. (2013): Awareness and knowledge on timing of mother-to-child transmission of HIV among antenatal care attending women in Southern Ethiopia: a cross sectional study. Reproductive Health 10 (66).

Ashimi, A.O; Omole-Ohonsi, A.; Amole, T.G., \& Ugwa, E.A. (2014): pregnant women's knowledge and attitudes to MTCT of HIV in rural community in North western Nigeria. west Africa ournal of medicine. 23 (1): 20-25.

Bartlett, W.C.; (1998): “AIDSLegal issues of federal concern”. Library of parliament (Research Branch) 
Bartlett, J. E., Kotlrik, J. W. \& Higgigs, C. C 2001): Organizational Research: Determining Appropriate Sample size in survey Research. Learning and performance Journal, page 43-50.

Cameron, A.C.; \& Trivedi, P.K. (1996): Data models for financial data. Statistical methods in finance.363-392.

Chinaeke, E.E; Osuala, C.F; Bathnna, M; Oigbu, C.E; Olakunde, B; Ramadhani, H.O; Ezeanolue, E.E; \& Ayudu, N.A.S. (2019): correlates of reported modern conceptive use among Postpartum HIV-positive women in rural Nigeria: an analysis from the moment prospective cohort study. Reproductive health 16:2.

De Cock, K.M.; Fowler, M.G.; \& Mercier, E. (2000): Prevention of mother-to-child HIV transmission in resource-poor countries: translating research into policy and practice.

JAMA; 283(9):1175-1182

Dean, C. \& Lawless, J.F. (1989): Test for detecting Overdispeson in Poisson regression Models. 84 (406):467-472.

Demissie, A; Deribaw, A; \& Abera, M. (2009): determinants of acceptance of voluntary HIV testing among antenatal clinic attendees at Dil Chora Hospital, Dire Dawa eastern Ethiopia. Ethiopia journal for health 23 (2):41-147.

Dismas, N. (2018): Modelling spatio-temporal patterns of disease risk for data with misalignment and measurement errors: An application on measles and HIV prevalence Data in Namibia.14-20

Essel, A.P. (2018): factors affecting adherences to anti-retroviral therapy among Women in selected health facilities in greater Accra region. M.sc Dissertation, University of Ghana. 20-44

Everitt, B.S. (2002): The Cambridge dictionary of statistics ( $2^{\text {nd }}$ ed). New York Cambridge University press. $178-185$.

Fanta, W; \& worku, A. (2012): Determinants for refusal of HIV testing among women attending Antenatal care in Gambella Region, Ethiopia. Reproductive health 9:8.3-11

Federal Ministry of Health (2014): National HIV Sero-prevalence Sentinel Survey among Pregnant Women Attending Antenatal Clinics in Nigeria. Department of Public Health National AIDS/STI Control Programme.

Greene, W. (2008): Functional Forms for the Negative Binomial Model for count Data. Economic Letters. 99:585-590.

HIV/AIDS and Human rights in Nigeria (2003): Background paper for HIV/AIDS policy Review Nigeria.

Iwelunmor, J; Ezeanolue E.E; Airhihebuwa, C.O; Obiefune, M.C, Ezeanolue, C.O; \& 
Ogedegbe, G.G. (2014): Socio-cultural influencing the prevention o mother-to-child transmission of HIV in Nigeria; a synthesis of the literature.

BMC public Health 14:771

Jemmy, X., Liu; Jennifer, S; Wilson, N.; Janumpall, S.; Sadler, P.; \& Padian, N. (2019): Conditional cash transfers to prevent mother-to-child transmission in low facilityDelivery settings: evidence from randomised controlled trials in Nigeria.

Jimmy, W. (2012): Logistic distribution. Wikipedia, the free encyclopedia.

Kleinaunm, D.G \& Klein, M (2010): Assessing discrimination performance of Binary Logistic models. ROC Curves.

Kuhn, L; Sinkala, M.j; Thea, D.M \& Aldrovandi, G.M. (2009): HIV prevention is not enough; Child survival in the context of prevention of mother-to-child HIV transmission in Mailman school of health: A win approach of literature Journal of the international AIDS society 12:36. 2-8.

Lawal, H.B (2003): Categorical Data analysis with SAS and SPSS application. London: Lawrence Erlbaum Associates, publishers.

Levesque, F.J; Harris M.F \& Russel G. (2013): Patient-centred access to health care. Conceptualizing access at the interface of health system and population international journal for equity in health 12:18. 3-8.

Lincetto, O; Motherbesoan, A.S; \& Munanja (2015): Antenatal care in in Afriaca.

Liu, J.X; Shen, J; \& Padian, N. (2019): Conditional cash transfers to prevent mother-to-child transmission in low facility-delivery settings: evidence from randomised controlled trials in Nigeria. BMC pregnancy and childbirth, 19:32

Malaju, M.T; \& Alene, G.D (2012): determinant factors of pregnant mother's knowledge on moter-to-child transmission of HIV and its prevention in Gondar town, North West Ethiopia. BMC pregnancy and childbirth 12:73

NACA (2019): Revised National HIV/AIDS strategic framework 2019-2021: National Agency for the control of AIDS framework. 9-30.

Nguyen, T.A; Osterhoff, P; Pham, Y.N Hardon, A; \& Wright (2009): Heath workers on quality of prevention of mother-to-child transmission and postnatal care of HIV infected women and children in Hanoi. Human resources for Health 7:39

Nigatu, T; \& Woldegebriel,Y. (2011): Analysis of the prevention of mother-to-child Transmission service utilization in Ethiopia. Productive Health 8:6 
Nwakaeogo, E.C. (2014): Factors influencing prevention of mother-to Child-transmission. M.sc dessertation, University of of South Africa.

Osumba, B.M. (2009): Do PMTCT programs leak by design or default. Examining the barriers to utilization of prevention of mother-to-child transmission of HIV services in Rift.

Otokpa, A.O; Lawoyin, T.O; Asuzu \& M.C (2013): HIV/AIDS -related knowledge and Misconceptions among women attending government-owned antenatal clinics in Gwagwalada area council of Abuja, Nigeria Africa journal of reproductive health. 17(1):114-21.

Padian, N.S.; Mccoy, S.I.; \& Karim, SS.; (2011): HIV prevention transformed: the new prevention research agenda. Lancet. 2011;378(9787): 269-278.

Park, H. (2013): An introduction to logistic regression: from basic concepts to Interpretation with particular attention to Nursing Domain.

Pielou, E.C (1977): Mathematical Ecology, New York. Wiley, A basic text on quantitative analysis in Ecology, containing two chapters on the analysis of Ecological diversity.

Puremelaun, B.P; Puthussey, S; \& Papas, Y. (2019): Attitudes and perceptions of pregnant Women towards the use of Anti-retroviral Therapy in Nigeria.

Women and birth journal volume 32. Pages 186-196.

Sampson D. (2018): factors influencing male involvement in antenatal care. M.sc

Dessertation. University of Ghana.21-50.

Thiede, M. \& Intyre, M.C. (2008): Information, communication and equitable access to Health Care.

UNICEF (2015): Global Summary of HIV Epidemic among Children (0-14 years), Western and Central Africa. 2015. Available from: https://data. unicef.org/wpcontent/uploads/2015/12/2016_West-and-CentralAfrica.xlsx.

UNICEF(2016): Nigeria PMTCT Fact Sheet. Available from: http://www.unicef.org/aids/files/Nigeria_PMTCTFactsheet_2010.pdf.

Wayne, W.; Lamorte, M.D. (2016): The binomial distribution. Boston University school of public Health.

World Health Organization (2015): Guideline on when to start antiretroviral therapy and on preexposure prophylaxis for HIV; September 2015.

World Health Organization (2017): Mother-to-child transmission of HIV. Available from: http://www.who.int/hiv/topics/mtct/en/. 